\title{
Comparison of the Shear bonding Strength of ION-Z GIC to a Resin Composite Using Different Adhesive Systems: RCT Study
}

Sana Lala ( $\sim$ sana.lala@hotmail.com )

Damascus University https://orcid.org/0000-0003-1524-1344

Thuraya Lazkani

Damascus University

Research article

Keywords: ION-Z GIC, Shear bonding strength, Resin Composite, Self-etching bond, Total-etching bond

Posted Date: June 1st, 2020

DOI: https://doi.org/10.21203/rs.3.rs-31621/v1

License: (c) (i) This work is licensed under a Creative Commons Attribution 4.0 International License.

Read Full License 


\section{Abstract}

\section{Background:}

In restorative dentistry we usually use Sandwich Technique for posterior restorations where GIC is placed below and a resin composite is placed over it. The bonding strength between these two materials are low. We are looking for the best adhesive system to put it in between. We think that the self-etching bond will give the best bonding strength between them whereas total etch will give lower bonding strength than self-etching system.

\section{Methods:}

ION-Z GIC was bonded to resin composite by using two different bonding agents. The thirty specimens used were prepared by using acrylic blocks with holes in each hole to retain the ION-Z GIC. The specimens were randomly divided into three groups:

Group I: Control group.

Group II: Total-etch adhesive was applied and cured over ION-Z GIC.

Group III: Self-etch adhesive was applied and cured.

The composite resin placed over the ION-Z GIC and cured.

The shear bond strength was measured by shearing of the bonded specimens on Universal Testing Machine (Model 114) using speed of $0.1 \mathrm{~mm} /$ minute.

The reading was tabulated and subjected to statistical analysis using ANOVA and Tukey's test.

\section{Results:}

The test showed statistically significant difference between Group III and Group I and between Group III and Group II. Group III had the highest shear bonding strength.

\section{Conclusion:}

Self-etch adhesive agent produces have better shear bond strength to ION-Z than total-etch adhesive and to the group without any bonding agent.

\section{Background:}

The improved performance of resin composites and the increasing demand for esthetic perfection has made the composite resin the main restorative material for posterior restorations. However, the clinician should be aware of certain disadvantages when using a resin composite, such as polymerization shrinkage, associated micro leakage, pulpal irritation and lack of anti cariogenicity. ${ }^{\{1\}}$ Sandwich 
Technique plays an important role in restorative dentistry, where glass ionomer cement (GIC) is placed below and a resin composite is placed over it. The superior micromechanical bond of resin composite to acid-etched enamel, the bond strength of glass lonomer to dentin and the ability of glass lonomer to release fluoride when in contact with oral fluids, combined with its low solubility, make the combination of these two materials a prudent step in improving clinical success. ${ }^{\{2-3\}}$ This technique was developed by McLean and others in 1985; they used the dentin adhesive properties of glass ionomer cements (GICs) to seal cavities and reduce microleakage. ${ }^{\{4\}}$ This technique benefits from the advantages of GIC fluoride release combined with esthetic resin material to enhance clinical serviceability. ${ }^{\{5\}}$

However, the bonding strength between conventional GICs and resin composite is low because of the lack of chemical bonding between these two materials. This could be attributed to the difference in setting reactions between dental composites and conventional GICs. ${ }^{\{5\}}$

Furthermore, failure also occurs due to sensitivity of the GIC to moisture and its progressive loss following acid etching. ${ }^{\{6\}}$

Moisture contamination during the initial setting of GICs can cause dissolution of the weak calcium polyacrylate chains, which can degrade their physical properties. ${ }^{\{7\}}$ In order to prevent moisture contamination during the rinsing procedure, it is mandatory to allow the initial setting of the glassionomer prior to the etching procedure. ${ }^{\{7\}}$ Clinically, this can be achieved by waiting for two-to-seven minutes for the initial setting of the GIC to be complete before start etching and rinse procedure ${ }^{\{7\}}$.

Detailed clinical techniques for bonding glass ionomer to dentin, followed by etching the enamel margin and glass ionomer lining, then bonding resin composite to etched enamel and glass ionomer have been described. ${ }^{\{8\}}$ The success of the resin composite-glass ionomer laminate restoration depends on the strength of the bond of the glass ionomer liner to dentin and the strength of the bond between the glass ionomer liner and the resin composite. ${ }^{\{8\}}$

GIC etching time has yet to be standardized. A 30-second or less etching time has been proposed in one study, ${ }^{\{9\}}$ while another study showed the average bond strength of 1,159 psi between composite and glass ionomer etched for 60 seconds. ${ }^{\{4\}} \mathrm{A}$ third study reports no significant difference between 30 - and 60 -second etching times. ${ }^{\{6\}}$ However, surface deterioration of glass ionomer cements following acid etching for longer than 15 seconds has been noted and recommendations for limiting the etching time has been made based on these SEM evaluations. ${ }^{\{4\}} \mathrm{A}$ study by Magnum and others recommended a 15second etching time before application of the bonding agent. ${ }^{\{5\}}$ The time-tested protocol of glass-ionomer composite bi-layered restoration has one clinical drawback. ${ }^{\{5\}}$ Due to the use of $37 \%$ phosphoric acid to etch glass ionomer, there is a need to rinse the acid before applying the bonding agent. ${ }^{\{5\}}$ In order to prevent moisture contamination during the rinsing procedure, which may affect the integrity of the glassionomer, it is mandatory to allow the initial setting of the glass ionomer before the etching procedure. ${ }^{\{5\}}$ 
This is clinically verified with the help of a sharp explorer ${ }^{\{5\}}$ after waiting for 5 minutes and 20 seconds (manufacturer's instructions GC ASIA Tokyo, Japan).

Since this procedure requires a waiting period, this technique is not popular among restorative dentists. $\left.{ }^{\text {7 }}\right\}$ The recent development of adhesive systems, including self-etch primers and glass-ionomer-based adhesives, might overcome this disadvantage, as they do not require etching and rinse procedure ${ }^{\{7\}}$.

Self-etching systems combine the functions of primer and adhesive components and do not need an "etch and rinse" phase, which not only decreases clinical application time, but also significantly reduces technique sensitivity. ${ }^{\{10\}}$ Another important advantage is that the infiltration of resin occurs simultaneously with the self-etching process, by which the risk of discrepancy between both processes is low or non-existent. ${ }^{\{10\}}$ The self-etch effect should be ascribed to non-rinsing, polymerizable monomers to which one or more carboxylic or phosphate acid groups are grafted ${ }^{\{7\}}$.

The glass-ionomer based adhesive was introduced in 1995 and is essentially a diluted version of the restorative resin-modified glass-ionomer cement Fuji II LC. ${ }^{\{11\}}$ Some recent research reports have demonstrated the favorable and somewhat unique characteristics of the adhesive, which were reported to have a fairly high tensile and shear bond strength and, according to a clinical report, were highly successful in retaining resin composite in non-undercut cervical cavities for a minimum of five years. ${ }^{\{21-}$ $13\}$

ION-Z is a glass ionomer-based radiopaque self-curing material with bactericidal and dentinogenic active ingredients, with induction of dentinal new formation, for the control of caries. ${ }^{\{14\}} \mathrm{ION}-\mathrm{Z}$ is indicated for the ART technique mainly due to its bactericidal power, but all the other features work together in leading to this indication: release of fluoride ions, fast acting, excellent viscosity, high mechanical strength. ${ }^{\{14\}}$ ION-Z Reinforced with Zinc has lower shrinkage during curing and excellent hygroscopic expansion: leading to a perfect marginal seal and it frees fluoride ions and acts as a rechargeable reservoir of this ion. ${ }^{\{14\}}$ In addition, it has high mechanical strength and chemical adhesion to enamel and dentin and high smoothness of the surface: providing greater comfort to the patient and favorable aesthetics. ${ }^{\{14\}}$

There is limited literature on the bond strength of ION-Z to composite resin with adhesive agents in between. However, bonding agents have been seen to improve the wettability of GIC to help it adhere to the composite resin ${ }^{\{15\}}$. Studies have shown that bonding agents which demonstrate a high degree of wettability, low viscosity, ${ }^{\{15\}}$ and low contact angle ${ }^{\{16\}}$ achieve a better union between GIC and the resin composite. Newer adhesive agents have undergone various modifications to improve the bond strength between the tooth and composite resin. However, there are very few studies conducted to compare the bond strength between ION-Z GIC and the composite, with different adhesive agents applied on the ION-Z GIC.

Hence, the present study was conducted to evaluate and compare the shear bond strength of ION-Z GIC to composite resin, using different generations of bonding systems applied on ION-Z GIC. 


\section{Methods:}

ION-Z GIC was bonded to a resin composite by using two different bonding agents, a Total-etch adhesive and a Self-Etch adhesive.

Preparation of the specimens:

The thirty specimens used in this investigation were prepared by using acrylic blocks. A total number of 30 acrylic blocks was prepared using a cuboidal plastic mold. In each block, four wells of $6 \mathrm{~mm}$ diameter and $2 \mathrm{~mm}$ depth were prepared by drilling holes in each block, to retain the ION-Z GIC.

With the aid of disposable micro applicators, one drop of the liquid on the holes walls was applied during 10 seconds, then the holes were washed (according to manufacturer's instructions).

The holes were then filled with self-cure ION-Z GIC by mixing it according to the manufacturer's instructions (one scoop of powder mixed with one drop of liquid) and covering the holes with glass plates to produce a smooth surface. The glass plate was carefully removed to ensure that the glass ionomer surface was smooth and not pitted. The specimens were randomly divided into three groups of 10 specimens each. The groups were:

Group I: Acts as a control group, no adhesive agent was applied between the ION-Z GIC and resin composite.

Group II: ION-Z GIC with a thin layer of total-etch adhesive was applied according to the manufacturer's instructions and cured, and then a cylinder of composite resin was added and cured over the specimen.

Group III: Same as group II, but a thin layer of self-etch adhesive was applied and cured over ION-Z GIC.

Immediately following this procedure, a transparent plastic ring, $4 \mathrm{~mm}$ in height, with a $5 \mathrm{~mm}$ internal diameter, was centered over the ION-Z GIC. The composite resin was condensed into a transparent plastic ring, using an incremental curing technique, above the ION-Z GIC substrate, and all sides of the specimen were cured to ensure complete curing of the material. Following the curing the plastic ring was removed. All the procedures were conducted at room temperature.00

Permission was taken from faculty of Dentistry to use the shearing measure machine at Faculty of Mechanical and Electrical Engineering. The shear bond strength was measured by shearing of the bonded specimens on Universal Testing Machine (Model 114) which was located in strength materials lab, using speed of $0.1 \mathrm{~mm} /$ minute. The shearing apparatus was constructed to grip the acrylic block, and a wedge blade system was designed to apply a shear force on the adhesive interface.

The reading was tabulated and subjected to statistical analysis using ANOVA and Tukey's test. Mean and standard deviation were calculated for each group by using the ANOVA test and intergroup comparison was done by the multiple comparison test-Tukey's test, which revealed a statistical significance among the groups. 


\section{Results:}

The mean shear bond strengths were calculated for each group. (Table 1)

The maximum shear bond strength values were recorded for Group III, where the self-etch adhesive was used, with the mean value of $9.151 \mathrm{MPa}$ and a standard deviation of 1.26. On the other hand, group I recorded minimum shear bond strength, with a mean of $6.158 \mathrm{MPa}$ and standard deviation of 0.912 . Group II with total-etch adhesive recorded a mean shear bond strength of 6.966Mpa and a standard deviation of 0.976. (Table 2).

The shear bond strengths (MPa) for the groups: (Table 1)

Table 1

\begin{tabular}{|lll|}
\hline Group I & Group II & Group III \\
\hline 7.92 & 9.32 & 10.48 \\
\hline 5.24 & 6.8 & 11.47 \\
\hline 5.74 & 5.37 & 10 \\
\hline 5 & 6.47 & 8 \\
\hline 5.84 & 6.43 & 8.08 \\
6.36 & 6.4 & 8 \\
6.52 & 7.66 & 8.2 \\
7.52 & 7.16 & 8.04 \\
6.14 & 7.17 & 10.14 \\
\hline 5.3 & 6.88 & 9.1 \\
\hline
\end{tabular}

Mean values (MPa) and standard deviation (SD) of the shear bond strength of the ION-Z bond to the composite by using different adhesive agents. (Table 2 )

Table 2

\begin{tabular}{|c|c|c|c|c|c|}
\hline \multicolumn{6}{|l|}{ ANOVA } \\
\hline \multicolumn{6}{|l|}{ strength bonding } \\
\hline & Sum of Squares & Df & Mean Square & $\mathrm{F}$ & Sig. \\
\hline Between Groups & 47.925 & 2 & 23.963 & 19.823 & .000 \\
\hline Within Groups & 32.638 & 27 & 1.209 & & \\
\hline Total & 80.563 & 29 & & & \\
\hline
\end{tabular}


Intergroup comparison was conducted by using the multiple comparison test (Tukey's test), which revealed a statistically significant difference among the groups. (Table3)

\section{Multiple Comparisons}

Table 3

Intergroup comparison was conducted by using the multiple comparison test (Tukey's test), which revealed a statistically significant difference among the groups. (Table3)

\section{Multiple Comparisons}

Dependent Variable: strength bonding

\begin{tabular}{|c|c|c|c|c|c|c|c|}
\hline & \multirow[t]{2}{*}{$\begin{array}{l}\text { (I) bonding } \\
\text { system }\end{array}$} & \multirow[t]{2}{*}{$\begin{array}{l}\text { (J) bonding } \\
\text { system }\end{array}$} & \multirow[t]{2}{*}{$\begin{array}{l}\text { Mean } \\
\text { Difference }(\mathrm{I}-\mathrm{J})\end{array}$} & \multirow[t]{2}{*}{$\begin{array}{l}\text { Std. } \\
\text { Error }\end{array}$} & \multirow[t]{2}{*}{ Sig. } & \multicolumn{2}{|c|}{$\begin{array}{l}95 \% \text { Confidence } \\
\text { Interval }\end{array}$} \\
\hline & & & & & & $\begin{array}{l}\text { Lower } \\
\text { Bound }\end{array}$ & $\begin{array}{l}\text { Upper } \\
\text { Bound }\end{array}$ \\
\hline \multirow{6}{*}{$\begin{array}{l}\text { Tukey } \\
\text { HSD }\end{array}$} & \multirow[t]{2}{*}{ no bonding } & total etching & $-.80700-$ & .49170 & .246 & $-2.0261-$ & .4121 \\
\hline & & self-etching & $-2.99200-^{*}$ & .49170 & .000 & $-4.2111-$ & $-1.7729-$ \\
\hline & \multirow[t]{2}{*}{ total etching } & no bonding & .80700 & 49170 & .246 & $-.4121-$ & 2.0261 \\
\hline & & self-etching & $-2.18500-{ }^{*}$ & .49170 & .000 & $-3.4041-$ & $-.9659-$ \\
\hline & \multirow[t]{2}{*}{ self-etching } & no bonding & $2.99200^{\star}$ & .49170 & .000 & 1.7729 & 4.2111 \\
\hline & & total etching & $2.18500^{\star}$ & .49170 & .000 & .9659 & 3.4041 \\
\hline \multirow[t]{6}{*}{ LSD } & \multirow[t]{2}{*}{ no bonding } & total etching & $-.80700-$ & .49170 & .112 & $-1.8159-$ & .2019 \\
\hline & & self-etching & $-2.99200-{ }^{*}$ & .49170 & .000 & $-4.0009-$ & $-1.9831-$ \\
\hline & \multirow[t]{2}{*}{ total etching } & no bonding & .80700 & .49170 & .112 & $-.2019-$ & 1.8159 \\
\hline & & self-etching & $-2.18500-{ }^{*}$ & .49170 & .000 & $-3.1939-$ & $-1.1761-$ \\
\hline & \multirow[t]{2}{*}{ self-etching } & no bonding & $2.99200^{\star}$ & .49170 & .000 & 1.9831 & 4.0009 \\
\hline & & total etching & $2.18500^{\star}$ & .49170 & .000 & 1.1761 & 3.1939 \\
\hline
\end{tabular}

The test showed statistically significant difference between Group III and Group I.

On the other hand, there is no difference between Group II and Group I. 


\section{Discussion:}

Glass Ionomer Cement has been used as a liner restoration in the posterior teeth due to its chemical bonding with the teeth. Nevertheless, because of its weak resistance toward the occlusal force, resin composite was used as a final restoration because of its cosmetical and physical properties.

On the other hand, we still have to find a way to get the best bonding strength between those two materials. Thus, we did this RCT study.

Thirty specimens were prepared with ION-Z and resin composite which was bonded by using two different kinds of bonding agents and the bond strength was measured.

The result of the study has concluded that a self-etch adhesive agent produces better shear bond strength to ION-Z, which is highly significant as compared to a total-etch adhesive and to the group without any bonding agent.

Proper bond strength between resin composite and ION-Z is necessary for the success of sandwich technique. Applying self-etch adhesive over ION-Z creates a stronger bond of composite resin to ION-Z compared with total-etch adhesive. The total-etch system needs two separate phases of rinsing and drying and has also a higher technique sensitivity. ${ }^{(17,18)}$ Moreover, the GIC surface may become weak during the drying phase. ${ }^{(19)}$

Owing to the acidic monomer in its composition, the self-etch adhesive does not need the etching phase, rinsing and drying. ${ }^{(20)}$ Self-etch adhesives are categorized into groups of mild, intermediate and strong based on their $\mathrm{pH}$ level and etching potential. ${ }^{(21)}$ Thus, their ability in creating a bond between the composite and ION-Z may be different. ${ }^{(21)}$

Our study showed that self-etch adhesive has a higher shear bond strength between the ION-Z and composite. Similar results were achieved by Kandaswamy et al. who reported that the mild self-etch bonding provided higher shear bond strength. ${ }^{(22)}$ This might be due to the lower acidity of the mild selfetch adhesive compared with the strong and intermediate self-etch adhesives. According to organic chemistry, when a weak acid invades something, it induces a minimum excitation in the ions, and hence the salt crumps formation will be minimal ${ }^{(23)}$. Cations such as $\mathrm{Ca} 2+$ and $\mathrm{Na}+$ that are not excited and are present in large amounts for effective interaction, especially in a conductive reaction medium like GIC, instigate strong ionic reaction with the bonding agents. ${ }^{(24,25)}$ It seems that the lower acidity of mild selfetch adhesive leads to the higher shear bond strength.

Additionally, in our research, the strong total-etch adhesive system in group II had a lower shear bond strength compared with the other group of self-etch bonding (group III). Some previous studies showed that using self-etch adhesive with a lower $\mathrm{pH}(1-0.8)$ created lower shear bond strength. $(22,26,27)$ 
Stronger acid neutralizes more cations, resulting in salt crumps formation. Therefore, the structure of the GIC is weakened and fragile, thus consequently the bond will be weakened ${ }^{(22,24)}$.

This research also found that self-etch adhesives improved the bond between the composite and ION-Z GIC compared with the total-etch adhesive.

Arora et al. reported that the self-etch adhesive caused a stronger shear bond between the composite and RMGIC. (28) Similar result was achieved in a study conducted by Chandak et al. on the same issue. (29) Another study also showed that using self-etch adhesive on the surface of RMGIC had the potential of creating a better bond strength with the resin composite. ${ }^{\left({ }^{30}\right)}$ This might be due to the acidic $\mathrm{pH}$ of selfetch adhesive. The acidic characteristic of self-etch adhesive causes superficial dissolution of GIC and consequently improves the bond between composite resin and GIC. ${ }^{(31)}$ Etching the surface of GIC with $37 \%$ phosphoric acid leads to dissolution of the lower layers of GIC matrix and therefore, would decrease the cohesive strength of the GIC which subsequently can affect the bond strength of the composite and GIC adversely. ${ }^{(30,32)}$ The porosity created on the GIC surface due to the phosphoric acid is different from that caused by self-etch adhesive. Superficial destruction by means of acid-etching leads to an undesirable surface bond with the composite. It seems that application of an acid with a similar acidity of the self-etch adhesive helps creating better shear bond strength.

On the other hand, self-etch adhesive has a lower viscosity compared with the total-etch adhesive. ${ }^{\left({ }^{3}\right)}$ In a research, Mount found that bonding with a lower viscosity caused low contact angle on the surface; thus, it improved the wettability and strengthened the bonding of resin composite and GIC (34) It seems that low viscosity of self-etch adhesive has more potential of wettability compared with the total-etch adhesive; so, it provides greater shear bond strength between the composite and GIC.

Previous studies on self-etch adhesives showed that this system bonds with the calcium in the structure of the teeth; ${ }^{(35)}$ therefore, it can possibly bond with the calcium in the structure of GIC and create a higher shear bond strength compared with the total-etch adhesive. ${ }^{(7)}$

From the results of the present study it can be concluded that the application of self-etch bond agents improves the wettability of ION-Z to adhere to composite resin, thus promoting a strong shear bond between ION-Z and the resin composite.

\section{Declarations:}

\section{Funding:}

No funding was received. The authors confirm the independence of this research completely from any governmental or non-governmental authorities or local /international organizations and the research is self-funded by Sana Lala. 


\section{Contributions:}

SL: Did the research, wrote the background, methods, results, discussion and conclusion section, designed the chart. TL: participated as the research supervisor, completed the statistical analysis, edited and checked up the research manuscript. All authors approved the final manuscript as submitted and agreed to be accountable for all aspects of the work.

\section{Ethical Declarations:}

\section{Ethical approval:}

This article does not contain any studies with human participants or animals performed by any of the authors. The research ethical approval was obtained from the scientific committee at the faculty of Dentistry.

\section{Consent to publication:}

Not applicable.

\section{Competing interests:}

The authors declared no potential conflicts of interest with respect to the research, authorship and/or publication of this article.

\section{Availability of data and materials:}

All necessary data are presented within the manuscript. All other materials and data are available upon request. For any more details regarding the data of this research please contact the corresponded author -Dr. Sana Lala.

\section{Acknowledgments:}

This research could not be completed without the help of Faculty of Mechanical and Electrical Engineering, Damascus University.

\section{References:}


1. Maldonado A, Swartz ML \& Phillips RW (1978) An in vitro study of certain properties of a glass ionomer cement Journal of the American Dental Association 96(5) 785-791.

2. Naughton WT \& Latta MA (2005) Bond strength of composite to dentin using self-etching adhesive systems Quintessence Internationa/ 36(4) 259-262.

3. Barkmeier WW, Shaffer SE \& Gwinnett AJ (1986) Effects of 15 vs 60 second enamel acid conditioning on adhesion and morphology Operative Dentistry 11(3) 111-116.

4. Sneed WD \& Looper SW (1985) Shear bond strength of a composite resin to an etched glass ionomer Dental Materials 1(4) 127-128.

5. Mangum Fl, Berry EA 3rd, Parikh UK \& Ladd D (1990) Optimal etching time of glass ionomer cement for maximum bond of composite resin Journal of the American Dental Association 120(5) 535-538.

6. García-Godoy F, Draheim RN \& Titus HW (1988) Shear bond strength of a posterior composite resin to glass ionomer bases Quintessence International 19(5) 357-359.

7. V. Gopikrishna, M. Abarajithan, J. Krithikadatta, and D. Kandaswamy (2009) Shear Bond Strength Evaluation of Resin Composite Bonded to GIC Using Three Different Adhesives. Operative Dentistry: July 2009, Vol. 34, No. 4, pp. 467-471.

8. McLean JW(1986) New concepts in cosmetic dentistry using glass-ionomer cements and composites California Dental Association Journal 14(4) 20-27.

9. Smith GE (1988) Surface deterioration of glass-ionomer cement during acid etching: An SEM evaluation Operative Dentistry 13(1) 37.

10. Sensi LG, Lopes GC, Monteiro S Jr, Baratieri LN \& Vieira LC (2005) Dentin bond strength of selfetching primers/adhesives Operative Dentistry 30(1) 63-68.

11. Inoue S, Abe Y, Yoshida Y, De Munck J, Sano H, Suzuki K, Lambrechts P \& Van Meerbeek B (2004) Effect of conditioner on bond strength of glass-ionomer adhesive to dentin/enamel with and without smear layer interposition Operative Dentistry 29(6) 685-692.

12. Tyas MJ \& Burrow MF (2002) Clinical evaluation of a resinmodified glass ionomer adhesive system: Results at five years Operative Dentistry 27(5) 438-441.

13. Burrow MF \& Tyas MJ (1998) Clinical evaluation of a resinmodified glass-ionomer adhesive system Operative Dentistry 23(6) 290-293.

14. www.fgm.ind.br

15. Hinoura KO, Onose K, Moore K, Phillips RW. Effect of bonding agent on the bond strength between glass ionomer cement and composite resin. Quintessence Int 1989;20:31-5.

16. Mount GJ. The wettability of bonding resins used in the composite resin /glassionomer "sandwich technique". Aust Dent J 1989;34:32-5.

17. Sharafeddin F, Moradian H. Microleakage of class II combined Amalgam-Composite restorations using different composites and bonding agents. J Dent Tehran Univ Med Scien. 2008; 5: 126-130.

18. Sharafeddin F, Yousefi $\mathrm{H}$, Modiri Sh, Tondari S. Micro-leakage of posterior composite restorations with fiber inserts using two adhesives after aging. J Dent Shiraz Univ Med Scien. 2013; 14: 90-95. 
19. Kasraie S, Shokripour M, Safari M. Evaluation of micro-shear bond strength of resin modified glassionomer to composite resins using various bonding systems. J Conserv Dent. 2013; 16: 550-554.

20. Sharafeddin F, Farhadpour H. Evaluation of Shear Bond Strength of Total-and Self-etching Adhesive Systems after Application of Chlorhexidine to Dentin Contaminated with a Hemostatic Agent. J Dent (Shiraz) 2015; 16: 175-181.

21. Van Meerbeek B, De Munck J, Yoshida Y, Inoue S, Vargas M, Vijay P, et al. Buonocore memorial lecture. Adhesion to enamel and dentin: current status and future challenges. Oper Dent. 2003; 28 : 215-235. [PubMed] [Google Scholar]

22. Kandaswamy D, Rajan KJ, Venkateshbabu N, Porkodi I. Shear bond strength evaluation of resin composite bonded to glass-ionomer cement using self-etching bonding agents with different $\mathrm{pH}$ : In vitro study. J Conserv Dent. 2012; 15: 27-31.

23. Morrison RT, Boyd RN. Organic chemistry. 5th ed. New Delhi: Prentice-Hall India Ltd.; 1987. p. 25.

24. Coutinho E, Van Landuyt K, De Munck J, Poitevin A, Yoshida Y, Inoue S, et al. Development of a selfetch adhesive for resin-modified glass ionomers. J Dent Res. 2006; 85: 349-353.

25. Gopikrishna V, Abarajithan M, Krithikadatta J, Kandaswamy D. Shear bond strength evaluation of resin composite bonded to GIC using three different adhesives. Oper Dent. 2009; 34: 467-471.

26. Crisp S, Wilson AD. Reactions in glass ionomer cements: III. The precipitation reaction. J Dent Res. 1974; 53: 1420-1424.

27. Poggio C, Scribante A, Della Zoppa F, Colombo M, Beltrami R, Chiesa M. Shear bond strength of onestep self-etch adhesives to enamel: effect of acid pretreatment. Dent Traumatol. 2014; 30: 43-48.

28. Arora V, Kundabala M, Parolia A, Thomas MS, Pai V. Comparison of the shear bond strength of RMGIC to a resin composite using different adhesive systems: An in vitro study. J Conserv Dent. 2010; 13: 80-83.

29. Chandak MG, Pattanaik N, Das A. Comparative study to evaluate shear bond strength of RMGIC to composite resin using different adhesive systems. Contemp Clin Dent. 2012; 3: 252-255.

30. Gopikrishna V, Abarajithan M, Krithikadatta J, Kandaswamy D. Shear bond strength evaluation of resin composite bonded to GIC using three different adhesives. Oper Dent. 2009; 34: 467-471.

31. 31. Hinoura K, Suzuki $H$, Onose $H$. Factors influencing bond strengths between unetched glass ionomers and resins. Oper Dent. 1991; 16: 90-95.

32. Inoue S, Abe Y, Yoshida Y, De Munck, Sano H, Suzuki K, et al. Effect of conditioner on bond strength of glass-ionomer adhesive to dentin/enamel with and without smear layer interposition. Oper Dent. 2004; 29: 685-692.

33. 33. Sharafeddin F, Zare S, Javnmardi Z. Effect of Home Bleaching on Microleakage of Fiberreinforced and Particle-filled Composite Resins. J Dent Res Dent Clin Dent Prospects. 2013; 7: 211217.

34. Mount GJ. The wettability of bonding resins used in the composite resin/glass ionomer 'sandwich technique'. Aust Dent J. 1989; 34: 32-35. 
35. Farah CS, Orton VG, Collard SM. Shear bond strength of chemical and light-cured glass ionomer cements bonded to resin composites. Aust Dent J. 1998; 43: 81-86. 